\title{
LAS VISIONES DE JULIANA DE NORWICH ENTRE EL ESTILO GÓTICO Y LA ABSTRACCIÓN
}

\author{
Victoria Cirlot \\ Universidad Pompeu Fabra \\ Barcelona, España \\ victoria.cirlot@upf.edu
}

RESUMEN / ABSTRACT

Este artículo plantea la relación entre las imágenes que resultan de la experiencia visionaria y el arte de la época. Se trata de comprobar cómo las imágenes visionarias se ajustan en muchos casos a las formas expresivas acunadas por la tradición iconográfica, lo cual deriva en parte de la función de las imágenes en las prácticas meditativas y devocionales. Las visiones de la reclusa Juliana de Norwich (1342/3-ca 1416), se ajustan al estilo gótico, tanto por temática (la Pasión de Cristo) como por el modo de tratamiento, destinado a provocar en el espectador/ lector emociones y un intenso sentimiento compasivo. Pero además este estudio tratará de mostrar cómo en la experiencia visionaria pueden emerger imágenes nuevas e insólitas que solo llegarán a construir un estilo o una tendencia artística siglos más tarde.

PALABRAS ClAVE: visión, imagen, gótico, abstracción, compasión.

THE VISIONS OF JULIAN OF NORWICH BETWEEN GOTHIC STYLE AND ABSTRACTION

This article presents the relationship between the images that emerge from the visionary experience and the art of the time. The aim is to verify how visionary images fit in many cases the expressive forms coined by the iconographic tradition, which derives in part from the function of images in meditative and devotional practices. The visions of the recluse Julian of Norwich (c. 1342-43-1416), conform to the Gothic style, both by theme (the Passion of Christ) and by the mode of treatment, designed to provoke in the viewer / reader emotions and an intense compassionate feeling. Furthermore, this study will try to show how in the visionary experience new and unusual images can emerge that will only come to build a style or an artistic tendency centuries later.

KEYWORDS: Vision, image, Gothic, abstraction, compassion.

Recepción: 27/07/2018

Aprobación: 08/11/2018 
Para Alois Maria Haas

Dos textos transmitidos en su integridad por cuatro manuscritos relatan la experiencia visionaria de la reclusa en una celda junto a la iglesia de saint Julien de Norwich. El primero de ellos es conocido como la versión breve y la primera frase puede concederle el título: A Vision showed to a Devout Woman. Está fechado hacia el año 1385, es decir, cuando Juliana de Norwich contaba con unos cuarenta años, y probablemente fue escrito como un testimonio (probatio) para que fuera aceptada su reclusión en la celda (McAvoy 51) ${ }^{1}$. Quizás recogió otro relato anterior surgido directamente de la experiencia visionaria acontecida el 8 o 13 de mayo del año 1373. Un manuscrito del siglo XV transmite esta versión (British Library, Ms Additional 37790) que está acompañada de otros textos de místicos ingleses como Richard Rolle, o bien continentales, como Jan van Ruusbroec, Heinrich Seuse, Bridget de Suecia o El espejo de las almas simples de Marguerite Porete sin que se le atribuyera a ella, y todo traducido al inglés medio. Ya recluida en la celda, aunque no en un aislamiento total, sino conectada al mundo bullicioso de la próspera ciudad de Norwich por medio de una ventana, en ese espacio intermedio, entre este mundo y el otro al que conducían los ritos litúrgicos a los que se abría una segunda ventana, la que daba a la iglesia (Georgianna 34), Juliana meditó sobre su experiencia visionaria y sus meditaciones dieron lugar a un segundo texto, conocido como versión larga, y al que también se le titula por la primera frase como A Revelation of Love (Watson, Jenkins). En este segundo texto fue integrado el primero y ampliado por medio de una intensa labor exegética. Hay en este segundo texto una clara voluntad de estructuración, de modo que las visiones aparecen ordenadas en dieciséis shewings, literalmente 'mostraciones', término que alterna con revelations (revelaciones) y con sight (visión), haciendo hincapié en el carácter pasivo de la visión en la medida en que no es tanto ella quien ve, sino Dios que le muestra (shew) la visión. Tres manuscritos del siglo XVII transmiten esta versión larga de forma íntegra (BNF ms fonds anglais 40; British Library, ms Sloane 2499; British Library, ms Sloane 3705), en la que la experiencia visionaria originaria, la del año 1373, se encuentra interrumpida por

La hipótesis de la probatio es de Vincent Gillespie, pero lo he leído en McAvoy, que no cita obra. 
reflexiones teológicas produciéndose la impresión de un texto construido por medio del principio del montaje y en el que la autoría se disuelve para generar múltiples puntos de vista y sobre todo una comunidad formada por un nosotros. Esta reescritura de la primera versión fue vivificada por nuevas experiencias visionarias (las de los años 1388 y 1393) y probablemente conoció una función distinta. Si bien la primera versión está dirigida a los contemplativos, la segunda busca un auditorio mucho más amplio, el de todos los cristianos (si es correcta la interpretación de evenchristen) y tiene la intención de involucrar al público en su propia experiencia haciéndolo partícipe de ella (Robertson 145). Con todo, hay que aclarar que es muy probable que el texto de las revelaciones de Juliana fuera un work in progress y que por tanto conociera fases distintas en su evolución, de las cuales solo ha quedado constancia de, al menos, dos de ellas, representadas por estas versiones breve y larga. Si bien son muchos los estudios que han puesto de manifiesto la originalidad de la teología de Juliana, hay que decir que se han dedicado pocos a comprender la novedad de sus imágenes. El hecho de que sus visiones nunca fueran ilustradas, quizás haya contribuido a ello, a diferencia del caso de otra gran visionaria, Hildegard von Bingen, cuyas visiones de Scivias y del Liber Divinorum operum fueron objeto de representación por parte de los miniaturistas (Cirlot, Vida 180-273). También en las visiones de Hildegard aparecen imágenes nuevas dentro de la iconografía de la época, por ejemplo, las trinitarias, pero siempre se resuelven según el estilo de su época (Cirlot, La visión 107-126). En cambio la novedad de las imágenes de Juliana no es tanto iconográfica como estilística. Me refiero a las visiones que Juliana denomina "visiones corporales" (bodily sight) que distingue de las "visiones espirituales" (gosthly sight), en su mayor parte centradas en la Pasión de Cristo, que es sin duda el gran tema de la pintura gótica influida por la espiritualidad franciscana. Dentro de estas visiones corporales hay dos revelaciones que concentran mi atención. Se trata de la primera y la cuarta revelación, a las que bien podríamos reunir bajo el título de "Visión en rojo"2. Mi intención consiste en mostrar cómo sus imágenes son inicialmente góticas y pueden reconstruirse con pinturas coetáneas, para de pronto dar un salto de siglos y situarnos ante una abstracción monocroma. 
La experiencia visionaria de Juliana sucedida en lo que parece un lecho mortuorio un día de mayo del año 1373, al segundo día de la enfermedad, entre las cuatro de la mañana y la tarde del día siguiente, se desencadenan por la percepción de un crucifijo que le muestra el sacerdote cuando va a visitarla. La activación del fenómeno visionario por medio de una obra de arte es un hecho conocido en los medios espirituales de la Edad Media. De hecho, esa era la función propia de la obra de arte, bien la de instalarte en un estado meditativo, bien la de provocar la visión. Jeffrey K. Hamburger ha puesto suficientemente de manifiesto la relación entre lo visual y lo visionario. La primera revelación de Juliana se inicia como una animación del crucifijo, lo cual constituía un hecho bastante frecuente entre las mujeres religiosas, sobre todo a partir de obras escultóricas (Jung 215). Cuenta Juliana que toda la habitación se oscurece menos el crucifijo sobre el que cae una intensa luz y de repente acontece la visión:

And in this, sodaynlye I sawe the rede blode trekille downe fro under the garlande alle hate, freshlye, plentefully, and livelye, right as methought that it was in that time that the garlonde of thornes was thyrstede on his blessede hede. Right so, both God and man, the same sufferde for me. I conseyvede treulye and mightelye that it was himselfe that shewed it me, withouten any meen. (A Vision 3, 10-14, A Revelation 4, 1-5)

En esto, de repente, vi correr la sangre roja bajo la corona, caliente $\mathrm{y}$ fresca y abundante, una corriente viva, como en el momento en que la corona de espinas fue apretada con fuerza contra su cabeza bendita. Comprendí, verdaderamente y con todo mi entendimiento, que era él, Dios y hombre, quien sufría por mí, que era él quien me lo mostraba sin ningún intermediario. (Libro de visiones 45$)^{3}$

Destaca en primer lugar el carácter repentino del suceso: sodaynlye. Acontece como cuando cae un rayo, de un modo totalmente inesperado, ciertamente fulminante. Pseudo Dionisio Areopagita en la carta III a Gayo lo definió así: "Llamamos repentino a lo que se nos presenta inesperadamente, como pasando de lo oscuro a la claridad" (Pseudo Dionisio 384). Nos encontramos ante un 
momento de la Pasión, representada en 1381 en un retablo para la catedral de Norwich por encargo del obispo Henry Despenser. El retablo está dividido en cinco secciones referidas a la flagelación, procesión al calvario, crucifixión, deposición y resurrección de Cristo (Fig. 1). En el siglo XIV, las Meditationes vitae Christi, en las que se cita con frecuencia a san Bernardo y que fueron



Fig. 1: Retablo Despenser. Catedral de Norwich. 1380-1390

falsamente atribuidas a Buenaventura, constituyeron el modelo de la meditación en la vida de Cristo para provocar en el creyente el sentimiento compasivo. Como san Bernardo, san Buenaventura entendió la meditación como una iniciación a la vida espiritual (Itinerarium mentis in Deum), considerando la compasión por el Cristo sufriente el primer escalón en el ascenso a Dios. En lengua vernácula en Inglaterra apareció The Prickynge of Love, una traducción de finales del s. XIV del célebre Stimulus amoris probablemente escrito por Jacobo de Milán pero atribuido también a san Buenaventura (Beckwith 57). La humanidad sufriente de Cristo se convirtió desde el siglo XIII en el objeto fundamental de representación del arte gótico generando una nueva forma afectiva que conocemos como compasión (Mc Namer). En este contexto artístico y espiritual hay que situar la visión de Juliana. Si comparamos el modo de representar la Pasión en el retablo Despenser y en la visión de Juliana, destaca fundamentalmente el carácter histórico del retablo frente al contemplativo de la visionaria. La imagen de la visión está más cerca de un icono como la Imago Pietatis que de una pintura escénica. La imago pietatis, deriva del icono bizantino que se difunde en Occidente en el siglo XII. Según la descripción que Erwin Panofsky hizo de ella en un estudio clásico aparecido en 1927, este tipo de representación procede de combinaciones inhabituales refiriéndose a conceptos que en el origen estaban separados, en especial, el Cristo en la cruz y el Cristo en la tumba: "Dispensado de toda exigencia de verosimilitud histórica, negando incluso la oposición entre vida y muerte, entre posición vertical y horizontal, este tipo reunió en un símbolo único y majestuoso, la Pasión, la quintaesencia de todo el sufrimiento de Cristo a 
favor del mundo -en un símbolo cuya grandiosidad solemne está destinada a expresar a la vez la muerte y el triunfo sobre la muerte. El nuevo tipo de imagen toma del crucifijo la actitud vertical del busto y la inclinación de la cabeza..." (13). Panofsky distingue entre 'imagen de devoción', 'imagen de historia escénica' e 'imagen de representación' hierática o cultual, y señala como la imagen de devoción (Andachtsbild), a diferencia de las otras, permite a la conciencia individual del espectador una inmersión contemplativa (kontemplative Versenkung) en el contenido meditado y deja de algún modo fundirse el alma del sujeto con el objeto (13-15). Por su parte Hans Belting hizo hincapié en el carácter de retrato de la imago pietatis, para sostener que esa forma es la característica fundamental por la cual la imago pietatis se distingue de las otras imágenes de la pasión como la crucifixión. Se trata sin embargo de un retrato de tipo particular: no es un verdadero icono-retrato al que le falta toda acción y no es un icono escénico en el que domina la acción (103). Entre las pinturas góticas destinadas a representar la Imago pietatis, la de Meister Francke fechada hacia 1420 podría servir como punto de referencia para la visión de Juliana. Michael Camille la colocó junto a la meditación de la Pasión de Cristo de Margarita Ebner, monja dominica (1291-1351) por el modo en que la visionaria habla de su cuerpo que experimenta una "grotesca

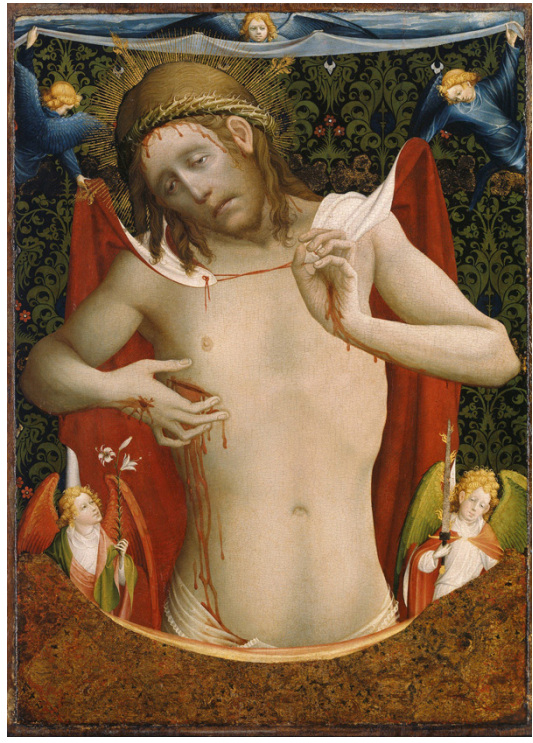

Fig. 2: Meister Francke, Man of sorrow, ca. 1430. Museo de Hamburgo maleabilidad", además de una pérdida de control, que se ajustaría al modo en que se resuelve el cuerpo de Cristo en la tabla de Leipzig del Meister Francke (más pequeño que las otras dos versiones del tema por parte del artista). Camille considera que la obra se presenta como "an object structuring the beholder's psychological identification an empathy with Christ"(183) (Fig. 2). Seguidamente Juliana da entrada a visiones espirituales. Cuando parece que ya ha concluido con esta primera revelación, Juliana insiste en que todo ha sucedido a un mismo tiempo ( $A$ Vision, 5; A Revelation, cap. 7). Se vuelve a centrar en la sangre: “...vi persistir el abundante derramamiento 
de sangre de su cabeza", para ampliar la versión breve introduciendo una tipología de las gotas de sangre:

The gret dropes of blode felle downe fro under the garlonde like pelottes, seming as it had comen oute of the veines. And in the coming oute they were browne rede, for the blode was full thicke. And in the spreding abrode they were bright rede. And whan it came at the browes, ther they vanished. And notwithstonding the bleding continued tille many thinges were sene and understonded, nevertheles the fairhede and the livelyhede continued in the same bewty and livelines.

The plentuoushede is like the dropes of water that falle of the evesing of an house after a grete shower of raine, that falle so thicke that no man may nomber, them with no bodely wit. And for the roundhede, they were like to the scale of hering, in the spreding of the forhede. (A Revelation 7, 10-20)

Las grandes gotas caían desde la corona como perdigones y parecían salir de sus venas. Cuando salían eran de un rojo pardusco, pues la sangre era muy espesa, y cuando se extendía se volvían de un rojo brillante. Cuando llegaban a las cejas, se desvanecían; y aun así, la sangre siguió corriendo hasta que yo hube visto y comprendido muchas cosas. Sin embargo, la belleza y la vivacidad de su rostro persistían, bello y vivo sin disminución. La abundancia se asemejaba a las gotas de agua que caen de los aleros de una casa después de un fuerte aguacero, cayendo tan copiosa que ningún ingenio humano podría contarlas. Y en su redondez, al derramarse sobre la frente, eran como escamas de arenque. (Libro de visiones 52)

El rojo inicial de la sangre adquiere ahora tonalidades: rojo pardusco, rojo brillante. También ahora la sangre como fluido adquiere consistencias diversas, la de perdigones, gotas de agua, escamas de arenque. La mirada se ha centrado ahora en la sangre misma y en su caída abundante. No resulta fácil encontrar una pintura o un dibujo que proporcione una imagen equivalente a la visión de Juliana, pues tal abundancia de sangre no suele ser objeto de representación en la pintura de la Pasión.

Con todo, un dibujo de la primera mitad del siglo XIV conservado en el Museo Schnütgen de Colonia (Fig. 3), cuya realización ha sido atribuida a una monja de un convento del Rin, muestra el cuerpo de Cristo cubierto enteramente por la sangre. San Bernardo aparece abrazado a la cruz transformada into a geyser of redeeming blood, en palabras de Jeffrey Hamburger (139). $\mathrm{Y}$ es que, en efecto, la sangre roja cae a grandes chorros y todo el cuerpo del 


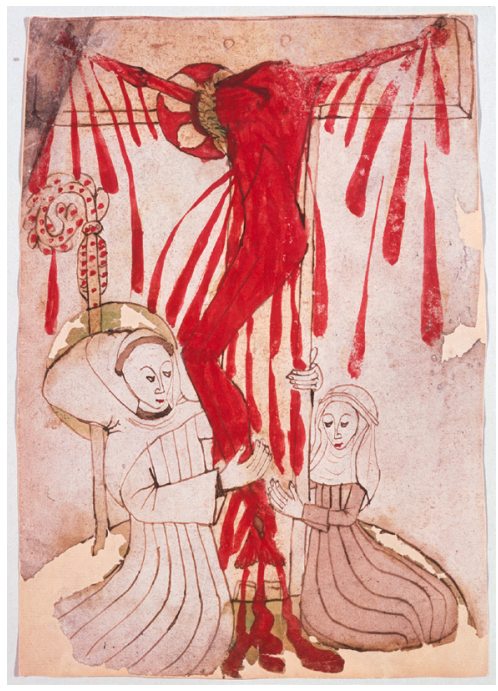

Fig. 3: Crucifixión, Köln, Museo Schnütgen, Inv. Nr. M340, primera mitad del s. XIV

crucificado está teñido de rojo. La imagen resulta impresionante por su intensa expresividad y crudeza, lo que contrasta con su reducido tamaño $(25.5 \times 18 \mathrm{~cm})$. El espectador siente como si los chorros de sangre fueran a alcanzarle, pero no lo hacen porque ni siquiera tocan ni a san Bernardo ni a la monja que está al otro lado de la cruz. ¿Cómo es esto posible? Ni una sola mancha roja se puede advertir en las túnicas de los dos personajes, ni tampoco sus manos que abrazan las piernas de Cristo o la madera ensangrentada de la cruz revelan rastro de sangre. ¿No pertenecerán a realidades distintas, una la del crucificado y su sangre, y otra la de los personajes al pie de la cruz? ¿No será el crucificado objeto de la visión de los que están arrodillados? También algunas miniaturas del siglo XV ofrecen esa misma intensidad a la hora de mostrar la sangre del crucificado. Así, el manuscrito de la British Library Egerton 1821 (Fig. 4), considerado como un ejemplo característico de libro devocional, pues en él mismo recayeron las manifestaciones emotivas por parte de sus lectores (como por ejemplo los besos que desgastan letras e imágenes), contiene un folio con la imagen de Cristo con la corona de espinas y todo él envuelto en sangre. Las gotas de sangre caen como gotas de lluvia. En este mismo manuscrito, en sus folios iniciales, fueron representadas gotas de sangre (Fig. 5).

En esta visión, el rostro de Cristo no ha desaparecido detrás de la abundancia de la sangre, sino que Juliana se refiere a él como un rostro bello y vivo. De hecho, la visión genera en Juliana sentimientos contradictorios y opuestos: "Esta visión era vívida y penetrante

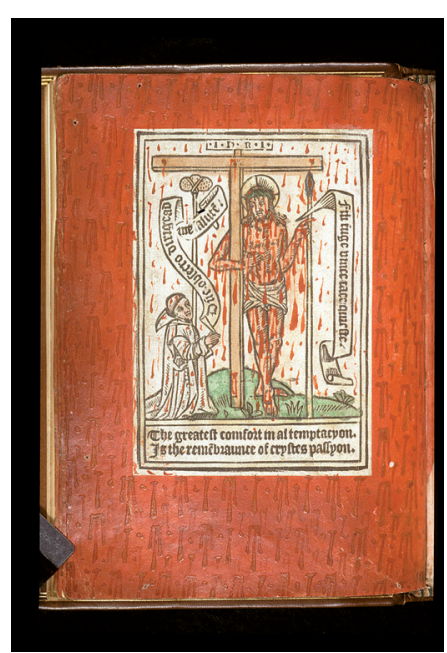

Fig. 4: British Library, Egerton 1821 , f. $9 v$, ca. 1490 
(quick and lively, A Revelation 7, 23), espantosa y horrible (hidous and dredfulle, 24), dulce y amorosa (swete and lovely, 24)". El espanto se conjuga con la dulzura, el horror con el amor, pero lo que parece cubrir a todos estos contrarios es una misma vida, el sentimiento de vida que despierta en Juliana la visión y que se refiere tanto al mismo rostro, lleno de belleza, como también al derramamiento

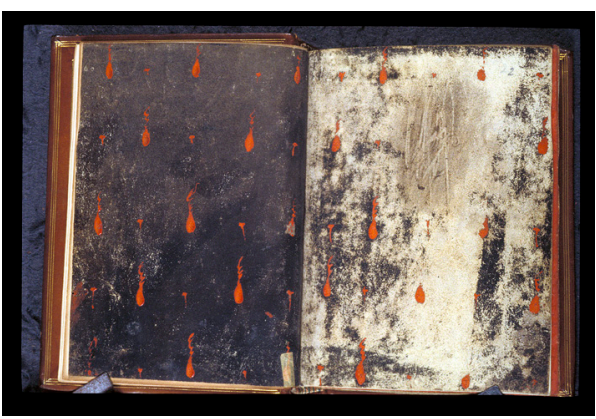

Fig. 5: British Library, Egerton 1821, f. $1 \mathrm{v}-2$, ca. 1490 de sangre. Las visiones de la sangre de Cristo, que remiten indudablemente a la vida, alternan en el Libro de Juliana con otras visiones corporales que se refieren al cuerpo de Cristo, y su carne, muestra visible de la muerte, a las que no nos vamos a referir en este artículo. Al concluir el relato de este primera revelación, Juliana precisa que tuvo espacio y tiempo para contemplarla (space and time to beholde it (A Revelation 8, 18-19), pero que la visión corporal cesó antes que la visión espiritual, que "continuaba en mi entendimiento".

La visión de la sangre vuelve a aparecer en la cuarta revelación. La fugaz alusión a la flagelación nos sitúa en la historia de la Pasión, aunque de nuevo Juliana elude el aspecto histórico para mostrarnos una imagen contemplativa. También alude a la carne, objeto de las visiones anteriores, pero lo hace de un modo rápido, para volver a centrar la mirada en la abundante caída de la sangre. Se trata de una imagen más intensa que la de la primera revelación $\mathrm{y}$, sobre todo, insólita para el estilo gótico. Reproduzco las dos versiones de esta visión porque contienen diferencias importantes:

And after this, I sawe, behaldande, the bodye plenteouslye bledande, hate and freshlye and lifelye, right as I saw before in the hede. And this was shewed me in the semes scourginge. And this ranne so plenteouslye to my sight that methought, if it hadde bene so in kinde for that time, it shulde hafe made the bedde alle on blode, and hafe passede on aboute. (A Vision 8, 20-24)

Después de esto, cuando miré, vi el cuerpo sangrando copiosamente, caliente, fresca y viva, como la había visto antes en la cabeza. Y esto me fue mostrado en la flagelación. Y la veía correr tan abundantemente que me pareció que si realmente hubiera sucedido allí, la cama y todo lo que estaba alrededor habría quedado empapado de sangre. (Libro de visiones 65) 
And after this I saw, beholding, the body plentuously bledin in seming of the scorging, as thus: the fair skinne was broken full depe into the tender flesh, with sharpe smitinges all about the sweete body. The hote blode ranne out so plentuously that ther was neither seen skinne ne wounde, but as it were all blode. And when it cam wher it shuld have falle downe, ther it vanished. Notwithstanding, the bleding continued a while till it might be seen with avisement. And this was so plentuous to my sight that methought, if it had ben so in kinde and in substance for that time, it shulde have made the bedde all on bloude, and have passede over all about. (A Revelation 12, 1-8) Después de esto, cuando miré, vi el cuerpo sangrando copiosamente a consecuencia de la flagelación, y era así. La hermosa piel estaba profundamente lacerada en la carne tierna por los atroces golpes asestados por todo el cuerpo. La sangre caliente corría tan abundantemente que ni la piel ni las heridas podían verse, pues todo parecía sangre. Y cuando descendía hasta donde debía haber caído, desaparecía. Sin embargo, la sangre siguió derramándose por un tiempo, como para que fuera observada atentamente. Yo la veía tan abundante que me pareció que si realmente y en substancia aquello hubiera sucedido allí, la cama y todo lo que estaba alrededor habría quedado empapado en sangre. (Libro de visiones 65 )

Todo es sangre y ya no puede verse nada más que sangre. En ese punto coinciden ambas versiones, aunque la larga amplía e intensifica el efecto. La abundancia y la copiosa caída parecen transgredir las fronteras entre el mundo físico y el mundo visionario. Pero Juliana distingue con claridad el espacio de su habitación donde ella yace en el lecho de muerte, del espacio visionario. En efecto, la sangre que ve no es materialmente real, no es "en sustancia", añade en la versión larga. Ante ella y ante nosotros se despliega una inmensa mancha roja que oculta el cuerpo, "ni la piel ni las heridas podían verse", precisa en la versión larga, "pues todo parecía sangre" (but as it were all blode). Esta cuarta revelación nos sitúa ante un mundo sin objetos, como habría dicho Kasimir Malevitch. Ciertamente nos encontramos ante una imagen abstracta. Con todo, la imagen no es únicamente roja, sino que para Juliana es sobre todo y fundamentalmente, sangre, la sangre de Cristo. Y su pensamiento se centra en su significado simbólico:

Than cam to my minde that God hath made waters plentuous in erth to our servys, and to our bodely eese, for tender love that he hath to us. But yet liketh him better that we take full holsomly his blessed blode to wash us for sinne, for ther is no licour that is made that 
liketh him so wele to geve us. For it is most plentuous, as it is most precious, and that by the vertu of the blessed godhead. And it i sour owne kinde, and all blissefully overfloweth us by the vertu of his precious love. (A Revelation 12, 9-15)

Entonces un pensamiento vino a mi mente. Dios ha creado aguas abundantes sobre la tierra para nuestro uso y el bien de nuestro cuerpo, por el tierno amor que nos tiene. Pero le place más que, por nuestro bien, aceptemos su bendita sangre para lavar nuestros pecados; no hay otra bebida creada que tanto le complazca darnos. Pues es la más abundante, la de mayor precio, y ello por el poder de la bienaventurada divinidad. Es de nuestra misma naturaleza, y fluye benditamente sobre nosotros por el poder de su infinito amor. (Libro de visiones 65)

En la nota de la edición de Edmund Colledge y James Walsh se plantea que probablemente Juliana tuviera en mente el texto trinitario tradicional de I Juan 5.6-8: "con sangre y agua, no sólo con agua, sino con agua y sangre. Y el espíritu santo testifica que Cristo es verdad...", lo que induce a concluir que este sería otro ejemplo de cómo Juliana sabe aunar la devoción popular con su conocimiento teológico de las Escrituras (343). Del simbolismo del bautismo con sangre pasa a mostrar una visión que solo transmite la versión larga, una imagen poderosa donde la sangre no solo parece inundar su lecho, sino que cubre los tres mundos, infierno, tierra y cielo:

Beholde and see the vertu of this precious plenty of his dereworthy blode! It descended downe into helle and brak her bondes and deliverd them, all that were there which belong to the courte of heven. The precious plenty of his dereworthy blode overfloweth all erth, and is redy to wash all creatures of sinne which be of good will, have ben, and shall be. The precious plenty of his dereworthy blode ascendeth up into heven in the blessed body of our lorde Jesu Crist, and ther is in him, bleding, preying for us to the father, and is shal be as long as us nedeth. And evermore it floweth in all heaven, enjoying the salvation of all mankind that be ther and shall be, fulfilling the number that faileth. (A Revelation 12, 17-25)

Mirad y ved el poder de esta preciosa abundancia de su preciosa sangre. Descendió a los infiernos y rompió sus cadenas, y liberó a todos aquellos que allí se encontraban y que pertenecían a la corte celestial. La preciosa abundancia de su preciosa sangre inunda toda la tierra, y está presta para lavar los pecados de todas las criaturas que son, han sido y serán de buena voluntad. La preciosa abundancia 
de su preciosa sangre ascendió al cielo en el cuerpo bendito de nuestro Señor Jesucristo, y allí entró a raudales, pidiendo al Padre por nosotros; así es y así será mientras tengamos necesidad de ello. Fluye a raudales por todo el cielo, regocijando en la salvación a toda la humanidad que allí se encuentra y se encontrará, hasta completar el número de los que faltan. (Libro de visiones 65-66)

La consideración de que la teología del pasaje es paulina (Romanos 5) no resta novedad a la imagen de la sangre descendiendo a los infiernos, inundando la tierra, ascendiendo al cielo y entrando a raudales. Nos introduce en otra dimensión, pues se han operado misteriosas transformaciones del espacio, como también ocurre en otras visiones. Barry Windeatt ha calificado la imagen de surreal: "In A Revelation this is transformed by a surreal visionary understanding of the potent blood streaming through hell, earth and heaven..." (105). Yo diría que Juliana vuelve a situarnos ante una imagen profundamente abstracta, desconocida para un público con una mirada formada por el estilo gótico. El carácter singular de las visiones de Juliana ha sido abordado por Vincent Gillespie y Maggie Ross que lo cifraron en su apofatismo derivado de un conocimiento inefable: "Apophatic images and surfaces are themselves non-figural but allow projection from within the viewer or perception derived from ineffable knowing" (57). La disolución de todo elemento figurativo para dar entrada a una imagen abstracta cuenta al menos con un ejemplo pictórico



Fig. 6: British Library, Egerton 1821, f. $7 \mathrm{v}$, ca. 1490 tal y como documenta el ms Egerton ya citado. El rojo cubre totalmente los folios $6 \mathrm{v}$ al $8 \mathrm{r}$, pudiéndose advertir además del color, una esquemática representación de las heridas de Cristo (Fig. 6). Nancy Thébaut ha dedicado un estudio a este extraordinario manuscrito, comprendiéndolo en el contexto de su época, dentro del culto de la preciosa sangre y de las maravillosas propiedades otorgadas a la sangre de Cristo, testimonio de su sacrificio y muerte, pero también fuente de vida y rebosante de efectos curativos. La sangre adquiere así un carácter metonímico, del mismo modo que sucede con la herida de Cristo. Separada del cuerpo ya sea la sangre ya sea la herida, se produce 
un efecto inusitado, geométrico en el caso de la herida que adopta la forma de una mandorla, abstracto en el caso de la sangre. Sin embargo, el rojo de la miniatura del ms Egerton, como el rojo de la visión de Juliana no son colores autónomos, sino que son siempre atributos de la sangre de Cristo. Con todo, el apofatismo de las visiones de Juliana corresponde al carácter de negación de la pintura abstracta que fundamentalmente lo es en virtud de su no figuración. La impresión de modernidad que producen estas visiones derivan de la sensación de encontrarnos ante pinturas abstractas. Parece entonces oportuno cambiar la perspectiva según la cual dividimos la historia en compartimentos cerrados para abrir el mundo visionario de Juliana a un diálogo con la aparición de la abstracción como una tendencia artística que encontrará todas sus posibilidades expresivas en el siglo XX. Vasili Kandinsky se nos presenta como el artista idóneo para entrar en la abstracción, tanto por su obra plástica, como por la teórica.

En Rückblicke (Mirada retrospectiva), Vasili Kandinsky dedicó páginas memorables a relatar sus experiencias artísticas. Publicado por vez primera en alemán por Der Sturm de Berlín en 1913 y en Moscú en 1918 en una nueva versión en ruso, Rückblicke, es coetánea y posterior a la creación de sus primeras obras abstractas y, por tanto, se trasluce en esta mirada retrospectiva la necesidad de comprender el nacimiento de la abstracción en su proceso creativo y de legitimar el gesto iconoclasta que le indujo a desterrar de la tela el objeto. El texto recoge el giro decisivo hacia la abstracción, que en cambio no se encuentra en Über das Geistige in der Kunst (De lo espiritual en el arte) de 1912, que reúne notas acumuladas entre 1904-1911, considerada junto a Punkt und Linie zur Fläche (Punto y línea sobre el plano, 1926) su obra teórica fundamental (Bouillon 24). Andrei Nakov ha dedicado un libro a indagar la complejidad de sentimientos de Kandinsky en relación con su primera obra abstracta, Pintura con Círculo de 1911, perdida durante mucho tiempo: en 1921 no acompañó al pintor en su exilio para quedarse en el museo moscovita de arte occidental e ir a parar en 1939 al Museo de Bellas Artes de Tbilissi. La obra hizo su aparición en Moscú en el mes de abril de 1989, en el momento de la primera retrospectiva de Kandinsky organizada por la Galería Tretiakov. Hans Konrad Roehtel (1977), el autor del Catálogo razonado no había visto la pintura original ni conocía su lugar de conservación, ignoraba 
sus dimensiones y solo contaba con una fotografía en blanco y negro, realizada por el asistente moscovita de Kandinsky, Vassili Bobrov. En la retrospectiva del artista que le dedicó la Tate Gallery en 2006, The path of abstraction, no fue mostrada esta obra, que además de la clara emancipación del círculo con respecto a todo tipo de objeto, contiene en el verso un autógrafo en el que se lee: "primera pintura no objetiva" y la fecha de 1911 (Nakov 1-21). No objetiva: bezpredmetny, el término empleado por Kasimir Malevitch en 1915 como "cualificación liberadora del arte en relación a toda dependencia con respecto a la naturaleza no pictórica"(Nakov 64). Nakov rastrea las referencias de Kandinsky a esta obra, pintada en su apartamento de Schwabing en Munich, para poner de manifiesto su ambivalencia, pues tanto la recordaba como testimonio indudable de su primera obra abstracta, como prefería olvidarla, diluyendo así en un pasado brumoso el poderoso gesto aniquilador del mundo fenoménico. Kandinsky fundamentó la legitimidad de dicho gesto en la "necesidad interior" que orienta toda su concepción de la espiritualidad en el arte (Nakov 160) y que Michel Henry entendió como la apertura de la pintura a lo invisible. Un nuevo rumbo tomaba a partir de entonces la pintura y es verosímil que el pintor sintiera ante ese acto un exceso de responsabilidad. Un pasaje de Rückblicke resulta revelador en lo que se refiere a ese paso del mundo del entorno a la imagen abstracta. Al referirse a una de sus obras, Alte Stadt (Ciudad antigua) expuesta en 1902 y realizada después de su viaje a Rothenburg que le dejó notablemente impresionado, Kandinsky se refiere a la hora del crepúsculo en Moscú que se resuelve en una mancha de color rojo y que corresponde al sonido de la tuba:

Auch in diesem Bild habe ich eigentlich nach einer gewissen Stunde gejagt, die immer die schönste Stunde des Moskauer Tages war und bleibt. Die Sonne ist schon niedrig und hat ihre vollste Kraft erreicht, nach der sie den ganzen Tag suchte, zu der sie den ganzen Tag strebte. Nicht lange dauert dieses Bild: noch einige Minuten und das Sonnenlicht wird rötlich von Anstrengung, immer rötlicher, erst kalt und dann immer wärmer. Die Sonne schmilzt ganz Moskau zu einem Fleck zusammen, der wie eine tolle Tuba das ganze Innere, die ganze Seele in Vibration versetzt. Nein, nicht diese rote Einheitlichkeit ist die schönste Stunde! (Kandinsky, Rückblicke V)

En este cuadro todavía estaba, a decir verdad, en busca de una cierta hora que era y sigue siendo la hora más hermosa del día en Moscú. El sol está ya bajo y ha alcanzado su mayor potencia, la que ha buscado y a la que ha aspirado durante todo el día. No es un espectáculo de larga duración: unos minutos más y la luz del sol se volverá rojiza por 
el esfuerzo, progresivamente, de un rojo primero frío, luego cada vez más cálido. El sol funde todo Moscú en una mancha que, como una tuba furiosa, hace entrar en vibración todo el ser interior, el alma en su integridad. ¡No es la hora del rojo uniforme la más bella! ${ }^{4}$

En la descripción del crepúsculo moscovita que se levanta ante su mirada como una imagen fugaz, de tan solo unos minutos, puede verse la ciudad fundida en una mancha (Fleck) roja. Es el momento en que el sol alcanza su máximo apogeo, el que ha buscado a lo largo de todo el día, para caer al poco rato. El pintor advierte que el rojo es cada vez más intenso, primero frío y luego caliente. La mancha roja no solo es visible, sino que también se oye, y ese sonido del color es el que hace vibrar el alma. Esa sinestesia de sentidos, la audición del color, corresponde a una percepción en la que no solo actúan los sentidos exteriores, sino que también intervienen los interiores convirtiendo la percepción en experiencia interior, como señaló Alois Maria Haas en su estudio sobre el poema de Hans Arp, Singendes Blau (Azul que canta). Pero esa mancha roja no es para Kandinsky la mejor hora. Se refiere a ella como una "unidad roja" (rote Einheitlichkeit). Ciertamente Kandinsky no es un pintor monocromo, ni la abstracción fue en sus inicios monocromía. Ni siquiera Kasimir Malevitch con su célebre Cuadrado negro sobre blanco es, como insistió Denys Riout, una pintura monocroma (Riout 40-50). En esta hora crepuscular moscovita Kandinsky no se detiene en la mancha roja, sino que espera a la explosión cromática como el momento definitivo:

Das ist nur der Schlussakkord der Symphonie, die jede Farbe zum höchsten Leben bringt, die ganz Moskau wie das fff eines Riesenorchesters klingen lässt und zwingt. Rosa, lila, gelbe, weisse, blaue, pistaziengrüne, flammenrote Häuser, Kirche -jede ein selbständiges Lied- der rasend grüne Rasen, die tiefer brummenden Bäume, oder der mit tausend Stimmen singende Schnee, oder das Allegretto der kahlen Äste, der rote, steife, schweigsame Ring der Kremlmauer, und darüber, alles überragend, wie ein Triumphgeschrei, wie ein sich vergessendes Halleluja der weisse, lange, zierlich ernste Strich des Iwan Weliky-Glockenturmes. Und auf seinem hohen, gespannten in ewiger Sehnsucht zum Himmel ausgestreckten Halse der goldene

$4 \quad$ Los pasajes traducidos al castellano están extraídos del libro de Michel Henry por lo que no cito páginas (Kandinsky, Mirada retrospectiva). 
Kopf der Kuppel, die zwischen den goldenen und bunten Sternen der andern Kuppeln die Moskauer Sonne ist. (V-VI)

No es sino el acorde final de la sinfonía lo que lleva cada color a su paroxismo vital y triunfa sobre Moscú entero haciéndolo resonar como el fortissimo final de una orquesta gigantesca. El rosa, el lila, el amarillo, el blanco, el azul, el verde pistacho, el rojo brillante de las casas, de las iglesias -cada uno con su melodía propia-, el césped de un verde rabioso, los árboles de bordón más grave o la nieve de mil voces que cantan, o el allegro de las ramas desnudas, el anillo rojo, rígido y silencioso de los muros del Kremlin, y, por encima de todo, dominándolo todo, como un grito de triunfo, como un aleluya olvidado de sí, el largo trazo blanco, graciosamente severo, del campanario de Ivan-Veliky. Y sobre su largo cuello, tendido, estirado hacia el cielo en una nostalgia eterna, la cabeza de oro de la cúpula que es, entre las estrellas doradas y abigarradas de las demás cúpulas, el sol de Moscú.

El paralelo entre colores y sonidos continúa. Kandinsky ve los colores, rosa, lila, amarillo, blanco, azul, verde pistacho, rojo flamígero (flammenrot), y los oye como el acorde final de una sinfonía que bien podría ser de Skriabine. Es un momento de éxtasis, en el que los árboles, los muros del Kremlin, las cúpulas, el campanario de Ivan Veliky y el sol de Moscú aparecen finalmente transfigurados en oro. Hay otro pasaje en Rückblicke de gran interés para las preguntas que suscita el carácter abstracto de la visión de Juliana. Me refiero al lugar que ocupa el color en la abstracción. Kandinsky recuerda lo que supuso para él la primera compra de los tubos de colores cuando contaba con trece o catorce años:

Die damalige Empfindung -besser gesagt: das Erlebnis der aus der Tube kommenden Farbe habe ich heute noch [...] diese sonderbaren Wesen, die man Farbe nennt -an und für sich lebendig, selbstständig, zum weiteren selbstständigen Leben mit allen nötigen Eigenschaften begabt und jeden Augenblick bereit, sich neuen Kombinationen bereitwillig $\mathrm{zu}$ beugen, sich untereinander zu mischen und unendliche Reihen von neuen Welten zu schaffen. (Kandinsky, Rückblicke XVII-XVIII) Lo que entonces sentí, o, mejor dicho, la experiencia que viví al ver el color saliendo del tubo, la sigo viviendo hoy [...], esos seres extraños a los que llamamos colores llegaban uno tras otro vivos en sí y para sí, autónomos y dotados de las cualidades necesarias para su futura vida autónoma $\mathrm{y}$, a cada instante, dispuestos a plegarse a nuevas combinaciones, a mezclarse unos con otros y a crear una infinidad de mundos nuevos. 
Los colores para Kandinsky son seres vivos, autónomos, prontos a ser combinados y a mezclarse para construir mundos nuevos. La abstracción implica el reconocimiento de la autonomía de los materiales pictóricos, de modo que la obra deja a un lado la representación y la mímesis para ser ella misma, por sí y para sí misma. La liberación de los colores de su dependencia con respecto a la realidad física y material se asemeja a la liberación de las palabras y la tentativa de hacer de la pintura una expresión autorreferencial se corresponde con un ansia análoga por parte de la lírica moderna, una revuelta que, por ejemplo, la música nunca ha tenido que experimentar. Con todo, para Kandinsky esa liberación de la esclavitud representativa se realiza para que sea posible la intervención del alma en el proceso creador. En De lo espiritual en el arte, Kandinsky afirma que "la armonía de los colores debe basarse únicamente en el principio del contacto adecuado con el alma humana". Y seguidamente considera que:

"Llamaremos a esta base principio de la necesidad interior". (Kandinsky, De lo espiritual 54)

Según Kandinsky, todo elemento es doble: exterior e interior. La visibilidad del color corresponde a su aspecto exterior, mientras que "su revelación interior consiste en la tonalidad afectiva a la que está asociado, que es lo único que constituye su realidad verdadera y lo que le confiere el ser" (Kandinsky, De lo espiritual 49). Al dejar a un lado el mundo de los objetos, "las apariciones sensibles pueden ser captadas en su pureza formal y su resonancia oída de nuevo" (55). La tesis principal de Kandinsky consistió en que cada color tiene una tonalidad afectiva propia:

No puede haber color -rojo, azul, amarillo- más que allí donde ese color es sentido, sobre el fondo de su "sentirse a sí mismo": en la vida invisible y solamente en ella. Pero el sentirse a sí misma de la vida, del color, es su pathos. El color no está ligado a una tonalidad en función de una asociación externa y contingente, variable según los individuos. Es en sí mismo, en la substancia fenomenológica de su ser y en su carne, como sensación y como subjetividad, esa tonalidad afectiva, esa sonoridad interior". ( Kandinsky, De lo espiritual 89)

En su libro sobre Kandinsky, Henry sintetiza la teoría kandinskyana de los colores considerando que "descansa enteramente en el vínculo tonalidad/ color, que no es otra cosa, a fin de cuentas, que la propia interioridad en sí misma del color en tanto que impresión pura, lo que llamamos su pathos". 
Como ejemplo de lo externo, lo visible del color, y lo interno, su tonalidad, elige el color rojo:

Que la experiencia del rojo no consiste en percibir un objeto rojo y ni siquiera el color rojo como tal, en considerarlo rojo, sino en experimentar su poder en nosotros: la impresión, esto es, en efecto, lo que elimina de la pintura toda mediación objetiva, la de los objetos en primer lugar, del sentido que se les puede dar, del pensamiento, de la "cultura" con sus variaciones según la época y los lugares... (Henry 93)

Más adelante y siguiendo con el color rojo, Henry comenta:

Para aislar el rojo de este entorno perturbador, Kandinsky tuvo una ingeniosa idea que bastaría para revelar su profundo instinto filosófico: arrancarlo a la realidad, a la superficie, a sus límites, a los demás tonos contiguos. Basta pronunciar la sola palabra "rojo" o concebir este color sin unir a él ninguna imagen ni, con mayor motivo, la percepción de un rojo real para que inmediatamente resuene una tonalidad en nosotros, la del rojo mismo separado de toda forma de cualquier otro color susceptible de alterar, y por tanto velar, su sonoridad propia. (107)

Se refiere Michel Henry a un pasaje de De lo espiritual en el arte donde Kandinsky contrapone el pensamiento o visión intelectual a su percepción, la palabra que alude al rojo, frente a su realidad material. Reproduzco todo el pasaje:

El color no se puede extender ilimitadamente. El rojo infinito sólo se puede pensar o ver intelectualmente. Cuando oímos la palabra "rojo", el "rojo" no tiene límites en nuestra imaginación. Los límites, si son necesarios, hay que imaginarlos casi a la fuerza. El rojo que no se ve materialmente, sino que se imagina de manera abstracta, provoca una cierta idea, precisa e imprecisa a la vez, que posee un tono puramente interior y físico. El rojo que resuena en la palabra no tiene una matización fina del tono rojo. Por eso digo que este ver espiritual es impreciso. Pero, al mismo tiempo, es preciso, ya que el sonido interno está desnudo, sin tendencias casuales hacia el calor, el frío, etc. Que llevan al detalle. El sonido interno se parece al sonido de una trompeta o de un instrumento imaginado con la palabra "trompeta", etc., en ausencia de los detalles. El sonido se imagina, sin las diferencias que en él se producen, cuando suena al aire libre, en 
un espacio cerrado, solo o con otros instrumentos, cuando lo produce un postillón, un cazador, un soldado o un virtuoso.

Cuando este rojo ha de ser reproducido en forma material (como en la pintura), tiene que a) poseer un tono determinado, elegido entre la serie infinita de los diversos rojos, es decir ha de ser caracterizado subjetivamente, b) tiene que ser limitado en la superficie, separarse de otros colores, que se hallan necesariamente en su compañía, que son inevitables y modifican (por delimitación y proximidad) la característica subjetiva (que obtiene una envoltura objetiva): aquí entra en juego la consonancia objetiva." (Kandinsky, De lo espiritual 57)

Al comentar el pasaje, Henry señala que Kandinsky está contraponiendo lo que filosóficamente se denominaría la "esencia del rojo" a los diversos coloridos posibles, como son el rojo de Saturno, el rojo cinabrio, el rojo inglés, la laca roja. Lo decisivo consiste en que toda esa variedad de matices del rojo conserva el "tono fundamental" (Henry 108). Existe entonces la tonalidad propia del rojo, que no varía apenas a pesar de la riqueza de sus matices. Kandinsky habla del pensamiento o la visión intelectual, pero ¿qué nos diría de la visión? ¿Qué nos diría de la visión de Juliana? Y no solo de la visión de Juliana, sino también de la imagen que provoca en el lector de su Libro. Destacaré solamente que en la visión, el rojo parece extenderse ilimitadamente. En ese sentido la experiencia visionaria es tan independiente de la realización material, pictórica, como lo que Kandinsky denomina el pensamiento o la visión intelectual. En la visión de Juliana es la sangre de Cristo el objeto de la visión, sangre que es naturalmente roja. El rojo no está desligado del objeto, pero en este caso la sangre es de este mundo y del otro, fluyente como la luz de la divinidad, y por tanto intensamente externa y visible, al mismo tiempo que interna e invisible. De hecho, la sangre de la visión de Juliana, como ya hemos podido comprobar, no es la sangre que sale del costado de Cristo, como nos la muestra la pintura gótica, sino una sangre "otra", que inunda toda la estancia, avanzando hacia el lector que la imagina a partir de las palabras de Juliana, es la sangre que, imparable, recorre los tres mundos.

La visión en rojo de Juliana de Norwich nos sitúa ante unas imágenes preconizadoras de la abstracción. No hay duda de que en ellas, como entendió Kandinsky, "el color rojo puede provocar una vibración anímica parecida a la de una llama, ya que el rojo es el color de la llama. El rojo cálido es excitante, hasta el punto de que puede ser doloroso, quizá por su parecido con la sangre" (Kandinsky, De lo espiritual 52). El rojo de la sangre del sacrificio de Cristo se une al rojo del amor del Espíritu Santo. La polaridad 
domina la visión en rojo y, justamente en virtud de ella, es expresión de esa interioridad y de la vida misma. Juliana no se estremece ante la visión en rojo que con todo no está sola, sino que alterna con otras visiones en las que el color deja paso a la materia, y a las que aquí no podemos referirnos. Si bien el inventor de la abstracción nos ha permitido confirmar la intuición de que la visión de Juliana era una visión abstracta, se impone ahora afrontar de un modo explícito algo obvio: la abstracción de la visión en rojo no es kandinskyana, en la medida en que no se mezcla con otros colores. La visión en rojo de Juliana es estrictamente monocroma. Ya vimos en la rememoración del crepúsculo moscovita, como Kandinsky no se detenía ante la unidad del color (rote Einheitlichkeit), sino que continuaba con una explosión cromática. Para comprender el carácter monocromático de la visión en rojo de Juliana, y también de los folios 6v al 8r del ms Egerton (Fig. 6) hay que recurrir a quien concedió fundamento a la monocromía dentro de la abstracción, o más allá de ella. Hay que recurrir a Yves Klein.

En la historia de la abstracción como tendencia o estilo comenzado en Europa en 1911 con la obra de Kandinsky a la que ya hemos aludido, el año 1955 hay que entenderlo como un momento de ruptura y de transformación del estilo. Es el año en que Yves Klein presenta en el Salón de las realidades nuevas en París su primera obra monocroma que no fue admitida. Como aprecia Denys Riout "el monocromo no es todavía una modalidad ordinaria de la pintura" y lo que genera de entrada es una problematización de la definición de la pintura como arte, en una difícil oscilación entre una hilaridad nihilista y la seriedad que implica la manifestación de lo absoluto (20). Riout sitúa la monocromía en una tradición perfectamente atestiguada que no es otra sino la de la iconoclastia fundamentada en el carácter infigurable de Dios. La iconofilia se argumenta en la medida en que el icono no deviene nunca ídolo, sino que la mirada debe transitar por la imagen para remontarse al modelo inmaterial, al prototipo, esto es, a la idea de la que procede. La consideración de que las visiones de Juliana son apofáticas me parece adecuada en la medida en que son abstractas y su unidad monocroma nos conduce justamente a lo absoluto. La teología cristocéntrica de Juliana no invalida en absoluto esta tesis, pues si Cristo es efectivamente la imagen del Padre, sus visiones parten de la humanidad de Cristo, esto es, de la figuración (la 
cabeza ensangrentada con la corona de espinas) para de pronto, al centrar la mirada en la sangre de Cristo, inundar de rojo todo el campo de visión, abriendo al lector a la imaginación de las realidades invisibles. Denys Riout sitúa a Yves Klein en esta tradición mística, alejándolo por tanto de los antecedentes monocromáticos de los siglos XVIII y XIX, siempre del lado de la risa (25). A pesar del rechazo del primer monocromo de Klein por parte de los abstractos, la vía monocromática se va configurando como una realidad, según se deduce de la tendencia generalizada de muchos artistas a reducir la gama de colores, suprimiendo casi los contrastes. Aunque estas obras no fueran auténticos monocromos, contribuyeron sin duda a actualizar la posibilidad: Clyford Still, Mark Rothko, Barnett Newman hasta los Black Paintings de Ad Reinhardt que suponen la consolidación definitiva. En marzo de 1960 tuvo lugar la primera exposición temática consagrada a la pintura monocroma en el Städtisches Museum de Leverkusen. La pintura monocroma se convierte en género, afirma Riout (68). En sus escritos, Yves Klein comenta la distancia que separa la abstracción de sus monocromos, según el nombre que diera a sus pinturas Pierre Restany:

Je cherche ainsi à individualiser la couleur, car j'en suis venu à penser qu'il y a un monde vivant de chaque couleur et j'exprime ces mondes. Mes tableaux représentent encore une idée d'unité absolue dans une parfaite sérénité; idée abstraite représentée de façon abstraite, ce qui m'a fait me ranger du côté des peintres abstraits. Je signale tout de suite que les abstraits, eux, ne l'entendent pas ainsi et me reprochent entre autres choses de refuser de provoquer des rapports de couleurs. (Klein 40)

Intento individualizar el color, puesto que he llegado a pensar que existe un mundo vivo de cada color y expreso esos mundos. Mis cuadros representan una idea de unidad absoluta en una perfecta serenidad; idea abstracta representada de manera abstracta, lo que me ha conducido a situarme en el lado de los pintores abstractos. Señalo de inmediato que los abstractos no lo entienden así y me reprochan entre otras cosas el rechazo a provocar las relaciones de los colores ${ }^{5}$.

Este testimonio de 1955 alude claramente al cambio que supuso la monocromía dentro de la abstracción, pero también que, al menos dentro de la conciencia del artista, no supuso una ruptura, sino por el contrario una continuidad 
transformadora. La idea que tiene Klein del color como ser vivo es análoga a la de Kandinsky: "Pour moi, les couleurs sont des êtres vivants, des individus très évolués qui s'intègrent à nous, comme à tout" (229). Con todo, destaca la diferencia fundamental: en lugar de ocuparse del contraste cromático, sucede la elección de un único color. Klein relató el proceso de la creación del monocromo: es en 1947 cuando le sobreviene la idea, "la visión consciente monocroma", que él entiende como el resultado de todas sus investigaciones apasionadas de aquella época (judo, contacto con los rosacruces, jazz, etc.), aunque no será hasta 1949 cuando esa idea se hace realmente consciente. Sucedió en Old Brompton Road de Londres, cuando trabajaba con el fabricante de marcos Robert Savage y entró en contacto directo con la materia, suprimiendo toda irregularidad en las capas, el blanco, el rojo, el oro y las hojas de oro "que volaban literalmente a la menor corriente de aire":

L'illumination de la matière dans sa qualité physique profonde, je l'ai reçue là, pendant cette année chez "Savage". Chez moi, en rentrant le soir dans ma chambre, j'exécutais des gouaches monochromes sur des morceaux de carton blanc et aussi de plus en plus je me servais beaucoup du pastel. (Klein 244)

La iluminación de la materia en su cualidad física profunda, la recibí allí, durante el año en "Savage". Cuando por la noche volvía a mi casa, a mi habitación, hacia gouaches monocromos sobre trozos de cartón blanco y cada vez más me servía de pastel.

No entraré en las técnicas desplegadas por Klein para conservar con vida el color una vez mezclado con la cola, el modo de fijar el pigmento sin alterarlo, sino que solo aludiré a su intención principal que era la de lograr un color perfectamente unido:

Mes toiles sont donc recouvertes chacune par une ou plusieurs couches d'une suele couleur unie après une certaine préparation du support et par de multiples procédés techniques. Aucun dessin, aucune variation de teinte n'apparait; il n'y a que de la couleur bien UNIE. En quelque sorte la dominante envahit le tableau. (Klein 40)

Mis telas están recubiertas cada una por una o más capas de un solo color unido después de una cierta preparación del soporte y por múltiples procedimientos técnicos. No aparece ningún dibujo, ninguna variación de tinta; no hay más que un color bien unido. De algún modo la dominante invade el cuadro. 
La unidad del color (rojo) que para Kandinsky era el momento que antecedía al verdadero espectáculo (la explosión cromática y sus contrastes) en la hora vespertina moscovita, se ha convertido para Klein en el objetivo de su pintura. La reducción del material pictórico a un solo color constituye un paso más en la vía apofática o negativa iniciada por la abstracción, una posibilidad que preside la visión de Juliana y la miniatura del ms Egerton, pero que también fue advertida por ejemplo, en Giotto, tal y como lo entendió el mismo Yves Klein:

...moi, je considère comme réel précurseur de la monochromie que je pratique, Giotto pour ses monochromes bleus d'Assise (appelés découpages du ciel par les historiens d'art mais qui sont bien des fresques monochromes unies) ... (Klein 258)

...considero como real precursor de la monocromía que practico a Giotto por los monocromos azules de Asís (llamados decoupages del cielo por los historiadores del arte, pero que son frescos monocromos unidos)...

Y a los frescos de Giotto añade las cuevas prehistóricas teñidas de azul cobalto, y los escritos de pintores que califica de pensamiento monocromo como van Gogh o Delacroix. En otro texto vuelve a referirse a la gran impresión que sintió al descubrir los frescos de la basílica de Asís, "frescos escrupulosamente monocromos, unidos y azules". De gran sutileza es la apreciación de que "aun admitiendo que Giotto tuviera la intención figurativa de mostrar un cielo puro y sin nubes, su intención era con todo absolutamente monocroma" (Klein 358). Creo que se podría decir lo mismo de la visión en rojo de Juliana de Norwich: por mucho que se refiera al rojo de la sangre de Cristo, la intención es totalmente monocroma y abstracta, al separar la sangre de cualquier parte del cuerpo de Cristo, y ser atributo de la sangre en una identificación total con ella, del mismo modo que en los lapidarios medievales los colores eran identificados con las piedras preciosas (Meier). En su libro sobre el fuego en la obra de Yves Klein, Pierre Restany se ocupó de la trilogía de los colores azul, oro, rosa. En febrero de 1960, Yves Klein participó en la exposición Antagonismes en el Museo de las Artes Decorativas de París presentando por vez primera en público un monogold tembloroso (panel dorado y recubierto de hojas de oro semipegadas sobre la superficie y por ello palpitantes al menor soplo de aire) que fue colocado junto a una zona de "sensibilidad pictórica inmaterial”. El oro frente al vacío, que Restany entiende como la apertura de la vía ígnea en proximidad con la alquimia del oro. En la trilogía 
monocroma, el fuego, atributo de las trinidades paganas, se convierte en el atributo del Espíritu Santo, el amor que une al Padre y al Hijo y que se designa por el color escarlata en la liturgia católica. Restany considera reveladora la transformación del escarlata en monopink dentro de la trilogía monocroma: el rosa figura al Espíritu Santo frente al oro del Padre y al azul del Hijo, que son el oro de la inmortalidad y el azul de la sensibilidad. La indagación de Klein sobre la llama de fuego le indujo a sustituir el rojo por el rosa. Restany cuenta que Klein intentó sin éxito realizar una Antropometría con sangre menstrual y que destruyó otras diez elaboradas con sangre de buey y firmadas con una huella digital con su propia sangre (61).

\section{BIBLIOGRAFÍA}

Beckwith, Sarah. Christ's body. Identity, culture and society in late medieval writings. Londres: Routledge, 1993.

Belting, Hans. L'arte e il suo pubblico. Funzione e forme delle antiche immagini della Passione. Bologna: Nuova Alfa, 1986 ( $1^{a}$ ed. 1981).

Bouillon, Jean Paul (ed.). "Introduction". Kandinsky, Regards sur le passé et autres textes (1912-1922). Écrits et propos sur l'art. París: Hermann, 2014 (1ª ed. 1974)

Camille, Michael. "Mimetic identification and Passion Devotion in the Later Middle Ages: A Double-sided Panel by Meister Francke". The Broken Body. Passion Devotion in LateMedieval Culture. Eds. A.A. MacDonald, H.N. B. Ridderbos and R.M. Schlusemann, Groningen: 1998.

Cirlot, Victoria. Vida y visiones de Hildegard von Bingen. Madrid: Siruela, 2009.

La visión abierta. Del mito del grial al surrealismo. Madrid: Siruela, 2010.

Georgianna, Linda. The Solitary Self. Individuality in the Ancrene Wisse. Cambridge Massachusetts: Harvard University Press, 1981.

Gillespie, Vincent, and Maggie Ross. "The apophatic image: the poetics of effacement in Julian of Norwich". The Medieval Mystical Tradition in England. Exeter Symposium V. Ed. Marion Glasscoe. Cambridge: Brewer, 1992. 53-77.

Haas, Alois Maria. Visión en azul. Estudios de mística europea. Madrid: Siruela, 1999.

Hamburger, Jeffrey, K. The Visual and the Visionary: Art and Female Spirituality in Late Medieval Germany. Nueva York: Zone Books, 1998.

Henry, Michel. Ver lo invisible. Acerca de Kandinsky. Madrid: Siruela, 2008 ( $1^{\mathrm{a}} \mathrm{ed}$. París 1988). Julian of Norwich. A book of Showings to the Anchoress Julian of Norwich, 2 vols. Ed. Edmund Colledge, James Walsh. Toronto: Pontifical Institute of Mediaeval Studies, 1978.

The Writings of: A Vision Showed to a Devout Woman and A Revelation of Love. Ed. Nicholas Watson y Jacqueline Jenkins. Pennsylvania: The Pennsylvania State University Press, 2006. 
A book of Showings. Ed. Edmund Colledge y James Walsh. Toronto: Pontificial Institute of Mediaeval Studies, 1978.

Libro de visiones y revelaciones. Ed. y trad. María Tabuyo. Madrid: Trotta, 2002.

Jung, Jacqueline E. "The tactile and the visionary: Notes on the Place of Sculpture in the Medieval Religious Imagination". Looking beyond. Visions, Dreams, and Insights in Medieval Art \& History. Ed. Colum Hourihane. Princeton: Princeton University Press, 2010. 203-240.

Kandinsky, Wassily. Über das Geistige in der Kunst. Munich: R.Piper \&Co., 1912.

"Rückblicke”, III-XXIX. Kandinsky 1901-1913. Berlín: Der Sturm, 1913.

Kandinsky, Vasili. Mirada retrospectiva. Trad. Alcira Nélida Bixio. Barcelona: Emecé Editores, 2002.

De lo espiritual en el arte. Trad. Genoveva Dieterich. Barcelona: Paidós, 1996.

Klein, Yves. Le dépassement de la problématique de l'art et autres écrits. Eds. Marie-Anne Sichère y Didier Semin. París: École Nationale Supérieure des Beaux Arts, 2003.

McAvoy, Liz Herbert. "Introduction: 'God forbede... that I am a techere': Who, or what, was Julian?”. A Companion to Julian of Norwich. Ed. Liz Herbert McAvoy. Cambridge: Brewer, 2008. 1-18.

McNamer, Sarah. Affective Meditation and the Invention of Medieval Compassion. Filadelfia: University of Pennsylvania Pres, 2010.

Meier, Christel. Gemma spiritalis. Methode und Gebrauch der Edelsteinallegorese vom frühen Christentum bis ins 18. Jahrhundert. Munich: Wilhelm Fink, 1977.

Nakov, Andrei. Kandinsky secret. L'énigme du premier tableau abstrait. París: Les Presses du réel, 2015.

Panofsky, Erwin. "Imago pietatis. Contribution à l'histoire des types du "Christ de Pitié"/'Homme de Douleurs" et de la "Maria Mediatrix" (1927). Panofsky, Erwin. Peinture et dévotion en Europe du Nord à la fin du Moyen Âge. París: Flammarion, 1997. 13-28.

Pseudo Dioniso Areopagita. Obras completas. Madrid: Biblioteca de Autores Cristianos, 1990.

Restany, Pierre. Yves Klein. Le feu au coeur du vide. París: La Différence, 1990.

Riout, Denys. La peinture monochrome. Histoire et archéologie d'un genre. Nîmes: Jacqueline Chambon, 2003.

Robertson, Elizabeth. "Julian of Norwich's 'Modernist Style' and the Creation of an Audience". A Companion to Julian of Norwich. Ed. Liz Herbert McAvoy. Cambridge: Brewer, 2008. 139-153.

Thébaut, Nancy. "Bleeding Pages, bleeding Bodies. A gendered Reading of British Library Ms Egerton”. Medieval Feminist Forum 45 (2009): 175-200.

Watson, Nicholas y Jacqueline Jenkins (ed.). The Writings of Julian of Norwich: A Vision Showed to a Devout Woman and A Revelation of Love. Pennsylvania: The Pennsylvania State University Press, 2006.

Windeatt, Barry. “Julian's Second Thoughts: The Long Text Tradition". A Companion to Julian of Norwich. Ed. Liz Herbert McAvoy. Cambridge: Brewer, 2008. 101-115. 